\title{
ASO Author Reflection: Optimizing Lateral Neck Dissection Extent of PTC by FNA-Tg
}

\author{
Xi Jia, MD' ${ }^{1}$, Runyi Tao, $\mathrm{BA}^{2}$, Ye Yang, $\mathbf{B A}^{1}$, Yuanbo Wang, $\mathrm{MD}^{1}$, Yan Liu, $\mathrm{MD}^{1}$, Aimin Yang, MD, PHD ${ }^{1}$, and \\ Rui Gao, MD, PhD ${ }^{1}$ \\ ${ }^{1}$ Department of Nuclear Medicine, The First Affiliated Hospital of Xi'an Jiaotong University, Xi' an, Shaanxi, China; \\ ${ }^{2}$ Department of Thoracic surgery, The First Affiliated Hospital of Xi'an Jiaotong University, Xi'an, Shaanxi, China
}

\section{PAST}

In the past decades, fine-needle aspiration cytology (FNAC) was the primary option for the diagnosis of suspicious lymph nodes on ultrasound in differentiated thyroid cancers (DTC). However, false-negative (6-18\%) and nondiagnostic (up to 20\%) results are common, resulting in high rates of misdiagnosis ${ }^{1}$.

To improve the diagnostic performance of FNAC, measurement of thyroglobulin $(\mathrm{Tg})$ concentration in the washout fluid of the needle used in FNAC (FNA-Tg) was introduced by Pacini et al. in $1992^{2}$. FNA-Tg was proved to have high accuracy for detection of nodal metastases from DTC, especially in patients previously treated by thyroidectomy. However, due to the lack of standardization of the sample preparing and assessing procedures, the cutoff value for diagnosis is still under debate. Moreover, the influence of serum $\mathrm{Tg}$ and thyroidectomy status on the performance of FNA-Tg is unclear.

\section{PRESENT}

This study highlighted the efficacy of FNA-Tg for detecting lateral neck lymph node metastasis in preoperative papillary thyroid cancer patients ${ }^{3}$. The superior sensitivity and excellent negative predictive values support its routine use as guidance for lateral neck dissection. Because the level

(C) The Author(s) 2021

First Received: 28 July 2021

Accepted: 30 July 2021;

Published Online: 12 August 2021

R. Gao, MD, PhD

e-mail: jacky_mg@xjtufh.edu.cn of FNA-Tg in the central compartment was easier to be by affected blood contamination or Tg leakage than that in the lateral compartment ${ }^{4,5}$, the additional diagnostic value of FNA-Tg is limited in central neck dissection planning. It is of note that, as compared to the absolute value, no diagnostic advantage was found for the difference or ratio between FNA-Tg and serum Tg.

A standardized FNA-Tg sample preparing procedure was introduced in this study ${ }^{3}$, a fixed $5 \mu \mathrm{L}$ of aspiration was added to $195 \mu \mathrm{L}$ of $\mathrm{Tg}$-free serum3. This could be a potential standard operating procedure with a fixed volume of aspiration sample and diluent matrix, thereby enabling comparisons among studies. Future multicenter data for a large-scale trial could provide robust evidence of diagnostic accuracy to the standard operating procedure of FNA-Tg.

\section{FUTURE}

FNA-Tg alone could accurately diagnose lateral lymph node metastasis in this study ${ }^{3}$. This might be a convenient and inexpensive choice in the following clinical application. Whereas an algorithm may be useful for future central lymph node diagnosis, including FNA-Tg, FNAC, and intraoperative frozen pathology.

ACKNOWLEDGEMENTS This study was supported by Major new medical technology in the First Affiliated Hospital of Xian Jiaotong University (XJYFY-2019ZD10), the Key Point Research Project of Shaanxi Province (No. 2019SF-078, No. 2017SF-258), and the National Science Foundation of China (No. 81871389).

DISCLOSURE All authors declare that they have no conflict of interest.

OPEN ACCESS This article is licensed under a Creative Commons Attribution 4.0 International License, which permits use, sharing, 
adaptation, distribution and reproduction in any medium or format, as long as you give appropriate credit to the original author(s) and the source, provide a link to the Creative Commons licence, and indicate if changes were made. The images or other third party material in this article are included in the article's Creative Commons licence, unless indicated otherwise in a credit line to the material. If material is not included in the article's Creative Commons licence and your intended use is not permitted by statutory regulation or exceeds the permitted use, you will need to obtain permission directly from the copyright holder. To view a copy of this licence, visit http://creativecommons. org/licenses/by/4.0/.

\section{REFERENCES}

1. Grani G, Fumarola A. Thyroglobulin in lymph node fine-needle aspiration washout: a systematic review and meta-analysis of diagnostic accuracy. J Clin Endocrinol Metab. 2014;99(6):1970-82.
2. Pacini F, Fugazzola L, Lippi F, et al. Detection of thyroglobulin in fine needle aspirates of nonthyroidal neck masses: a clue to the diagnosis of metastatic differentiated thyroid cancer. $J$ Clin Endocrinol Metab. 1992;74(6):1401-4.

3. Jia X, Wang Y, Liu Y, et al. Thyroglobulin measurement through fine-needle aspiration for optimizing neck node dissection in papillary thyroid cancer. Ann Surg Oncol. 2021. https://doi.org/10. 1245/s10434-021-10549-2.

4. Al-Hilli Z, Strajina V, McKenzie TJ, et al. Thyroglobulin measurement in fine-needle aspiration improves the diagnosis of cervical lymph node metastases in papillary thyroid carcinoma. Ann Surg Oncol. 2017;24(3):739-44.

5. Wang J, Jiang X, Xiao G, Zhou W, Hu Y. Excellent diagnostic performance of FNA-Tg in detecting lymph nodes metastases from papillary thyroid cancer. Future Oncol. 2020;16(33):2735-46.

Publisher's Note Springer Nature remains neutral with regard to jurisdictional claims in published maps and institutional affiliations. 